\title{
ATENCIÓN AL PACIENTE VIH/SIDA: LEGISLACIÓN Y BIOSEGURIDAD ODONTOLÓGICA EN COLOMBIA
}

\author{
Blanca Lucía Acosta de Velásquez*
}

Resumen: Este artículo describe normas universales de bioseguridad en la atención odontológica, particularmente las referidas a la atención de personas infectadas con VIH/SIDA, al tiempo que pasa revista a leyes y decretos relativos al tema vigentes en Colombia.

Establecer la rutina de evaluar, controlar y prevenir accidentes de trabajo e infecciones asociadas a la práctica odontológica garantiza una mejor atención y calidad de vida, tanto para los pacientes como para el personal de salud.

Palabras clave: VIH/SIDA, legislación, bioseguridad, infecciones, odontología, transmisión sexual

\section{CARE FOR HIV/AIDS PATIENTS: NORMS AND BIOSECURITY FOR ORAL HEALTH IN COLOMBIA}

Abstract: The present article describes biosecurity universal norms for dental care, specifically those referred to care of persons with HIV/AIDS, and also it reviews laws and norms at Colombia with respect to the topic.

It establishes the routine of evaluating, controlling and preventing accidents at work and infections associated with dental health practices, guaranteeing a better care and quality of life both for patients and for health personnel.

Key words: HIV/SIDA, norms, biosecurity, infections, dental health, sexual transmission

\section{ATENÇÃO AO PACIENTE VIH/AIDS: LEGISLAÇÃO E BIOSSEGURANÇA ODONTOLÓGICA NA COLOMBIA}

Resumo: Este artigo decreve normas universais de biossegurança na atenção odontológica, particularmente no que se refere aos cuidados de pessoas infectadas com o VIH/AIDS. Faz também uma revisão das leis e decretos relacionados com o tema vigentes na Colombia. Estabelecer uma rotina de avaliação, controle e prevenção de acidentes de trabalho e infecções associadas à prática odontológica garante uma atenção melhor e qualidade de vida, tanto para os paceintes como para os profissionais da saúde.

Palavras chave: VIH/AIDS, legislação, biossegurança, infecções, odontologia, transmissão sexual

* Fellow Epidemiología VIH/SIDA Programa Fogarty, Universidad de Miami. Coordinadora Unidad de Investigación Colegio Odontológico Colombiano Sede Santiago de Cali

Correspondencia: bacosta@odontologico.edu.co 


\section{Generalidades del VIH/SIDA}

Desde su aparición hace 24 años el síndrome de inmunodeficiencia adquirida (SIDA), secundario a la infección por el virus de inmunodeficiencia humana $(\mathrm{VIH})$, ha sido el causante de la muerte de más de 20 millones de personas en el mundo, donde actualmente existen entre $34 \mathrm{y}$ 46 millones de portadores del VIH/SIDA. Anualmente, esta cifra se incrementa en un promedio de cinco millones y mueren tres millones de personas por esta enfermedad, siendo la principal causa de muerte en todo el mundo. Para 2003 solamente se daba tratamiento a 400.000 pacientes con esta patología(1).

En Colombia, durante el primer trimestre de 2005, Bogotá y el Valle del Cauca ocuparon los primeros lugares en reporte de nuevos casos de VIH/SIDA. En este país, la epidemia sigue estando concentrada en la población de más alto riesgo y mayor vulnerabilidad; el grupo de edad más afectado está entre los 15 y 44 años, seguido por el de 45 a 64 años(2). Aunque inicialmente se consideraba que era una enfermedad más prevalente en hombres, se ha demostrado que continúa la feminización y, actualmente, se encuentra una relación hombre/mujer de 3:1(3), dando como resultado que el $37 \%$ de los adolescentes que viven con VIH/SIDA son mujeres(4). Los parámetros poblacionales de atención de pacientes en las clínicas del Colegio Odontológico Colombiano, sede Santiago de Cali, entre 2000 y 2004, mostraron que el 57\% de la población tenía entre 15 y 44 años y que el $67 \%$ eran mujeres(5), revelando que se está manejando una población muy similar a la que tiene mayor riesgo de infección por VIH.

Se estima que el $90 \%$ de las personas con VIH/SIDA desarrollarán al menos un problema bucal relacionado con su patología. En muchos casos, éste puede ser el primer indicio relacionado con la infección por VIH. Estos pacientes requieren mayor atención odontológica que los no infectados: su sistema inmune está comprometido y, cuando ya reciben tratamiento, algunos medicamentos antirretrovirales disminuyen la salivación. Todo lo anterior aumenta el riesgo de caries, enfermedad periodontal y otro tipo de lesiones en la boca, como crecimientos celulares anormales, infecciones bacterianas e infecciones vírales o por hongos, haciendo necesario que consulten en más oportunidades y requieran de intervenciones tempranas para prevenir daños mayores.

Teniendo en cuenta el concepto mundialmente aceptado de que la atención temprana produce beneficios importantes en el paciente infectado con VIH, alterando posiblemente de manera positiva el curso natural de la enfermedad, y debiendo ampliar el acceso del servicio odontológico para los que más lo necesitan, se hace indispensable conocer y manejar la legislación colombiana respecto del VIH/SIDA y cuáles son las normas internacionalmente reconocidas de bioseguridad que garantizan una atención integral al paciente, dentro de altos estándares de calidad, sin omitir tres principios fundamentales de los derechos humanos, a saber: autonomía del paciente para tomar sus propias decisiones en materia de salud; beneficencia/no-maleficencia, en el sentido de que toda intervención en salud deberá propender hacia el bienestar y no perjudicar al paciente, y justicia, en cuanto igualdad de oportunidades para acceder a tratamiento y al sistema de salud. "Los derechos humanos son preexistentes a toda forma de organización política o jurídica, son inalienables ya que no se pueden quitar o ceder y son inherentes al ser humano(6)".

\section{Legislación sobre VIH/SIDA}

Colombia participó activamente en la elaboración del Manifiesto de Montreal, en 1989, para defender los derechos de las personas afectadas por esta enfermedad y, en 1997, legisló al 
respecto. Con base en la Constitución de 1991 y en la Ley 100 de 1993, se estableció el Decreto 1543 de 1997(7), que continúa vigente, por el cual se reglamenta el manejo de la infección por el VIH/SIDA y de otras enfermedades de transmisión sexual (ETS). Casi simultáneamente fue creado el Consejo Nacional de Seguridad Social en Salud y se expidieron las Guías de Atención para el desarrollo de las acciones de protección específica y detección temprana y para la atención de enfermedades de interés en salud pública, como lo es el VIH/ $\operatorname{SIDA}(8)$.

En el Decreto 1.543 se define la terminología y se regulan las actividades diagnósticas, de atención integral, de promoción y prevención, de vigilancia epidemiológica y las medidas de bioseguridad respecto de los pacientes con VIH/SIDA; se establece la normatividad de investigación en concordancia con la Resolución 8.430 de 1993; se fijan los mecanismos de organización y coordinación del Programa Nacional de Prevención y Control de ETS y SIDA, y se crea el Consejo Nacional del SIDA y sus dependencias. Igualmente, se estipulan los derechos y deberes de pacientes y de los prestadores de los servicios de salud; además, el decreto brinda el marco de referencia frente a las posibles sanciones por incumplimiento de la legislación, tanto de parte de los pacientes como del personal de salud.

Es importante destacar la obligatoriedad de dar atención a los pacientes VIH/SIDA, según asignación de responsabilidad, por nivel de atención y grado de complejidad. También, la prohibición de solicitar pruebas de VIH para que el paciente acceda a los servicios de salud y el deber de impartir promoción, prevención y educación en salud al personal a su cargo, además de a pacientes y familiares del paciente con el fin de que puedan disfrutar una comunicación plena y clara con el equipo de salud.
En concordancia con lo estipulado en los Capítulos II y III del Código de Ética del Odontólogo Colombiano -Ley 35 de 1989(9), en el Código de Ética Médica-, Ley 23 de 1981(10) y dentro del marco del protocolo de atención integral, emanado del Ministerio de la Protección Social.

Así como existe la obligación de brindar atención al paciente VIH/SIDA, éste también tiene una serie de obligaciones, tanto con el odontólogo como con el equipo de salud: informar su condición de salud de manera oportuna cuando solicite algún servicio asistencial; no infectar, es decir, abstenerse de donar sangre y órganos, así como de realizar actividades que conlleven riesgo de infectar a otras personas, cuando conozca su situación de portador del VIH.

Esta legislación establece que se investigue la posible existencia de delitos por propagación de epidemia, violación de medidas sanitarias y las señaladas en el Código Penal, como sanción a los pacientes que trasgredan la norma. Además, el incumplimiento de la ley por instituciones públicas o privadas, y por personas naturales o jurídicas será sancionado de acuerdo con lo estipulado en la Ley 100 de 1990(11), en la Ley 35 de 1989 y en la Ley 23 de 1981.

\section{VIH/SIDA y bioseguridad}

Las estadísticas internacionales y nacionales de accidentabilidad ocupacional y riesgo biológico en el sector salud son muy similares a las locales. Para Cali, se encontró una prevalencia del 42,6\% en trabajadores del área de la salud y, de éstos, el 19,8\% presentaban tres o más accidentes en el sitio de trabajo; sin embargo, un $27,5 \%$ no lo notificaron. En este mismo estudio se encontró que el $65,5 \%$ de ellos no tenía vacunación para hepatitis B (VHB) y un $16,4 \%$ eran seropositivos para esta enfer- 
medad. La punción fue la lesión más frecuente, con un $69,2 \%$, y heridas en el $21,8 \%$ de los casos; estas lesiones habían sido producidas por agujas hipodérmicas huecas $(59 \%)$ y por instrumentos cortopunzantes $(18 \%)$. Se reportó una tasa de incidencia de lesiones accidentales en odontólogos del 10,2\%; en auxiliares, higiene oral en un $5,4 \%$, y en auxiliares de odontología en un 5,2\%. Estas cifras sólo fueron superadas por las encontradas en relación con bacteriólogos y laboratoristas. El estudio reveló que solamente una tercera parte de los trabajadores implicados en accidentes siguieron los pasos del protocolo de bioseguridad en los procedimientos del trabajo.

En el medio internacional, entre trabajadores de salud se manejan prevalencias de transmisión de VIH/SIDA por pinchazo o corte del $0,3 \%$, de VHB del 6 al 30\% y de hepatitis C (VHC) del 1,8 al 3\% (las cifras más altas corresponden a no inmunizados). El contacto con heridas en mucosa o piel ha arrojado una prevalencia de infección de $0,04 \%$ para $\mathrm{VIH} /$ SIDA, pero no está cuantificado para VHB y VHC.

Para determinar la gravedad de la lesión, se tiene en cuenta una serie de atenuantes tales como: profundidad de la herida, presencia de sangre visible en el instrumental, que el dispositivo haya estado dentro de una vena o arteria, que el paciente tenga diagnóstico de SIDA o tenga resistencia farmacológica, que falte tratamiento antirretroviral después de la exposición o que la profesional de salud se encuentre en embarazo. "El riesgo de seroconversión, después de una lesión en el trabajo, con exposición directa de sangre infectada, es 50 veces mayor a favor de VHB (25\%) frente al VIH $(0,5 \%)(12)$ ". Se debe tener presente que no existen medios para determinar si el paciente que se atiende es portador de enfermedades infecciosas; la historia clínica no es un indicador absoluto de que el paciente no padece ninguna afección, pues éste puede ignorar que se encuentra enfermo y es portador del VIH.

De todas maneras, no se puede olvidar que el riesgo de infección se reduce si se observan las precauciones universales y se evita el tratamiento directo del paciente cuando el operador tiene lesiones exudativas en piel o dermatitis supurativa. Las precauciones universales han sido estipuladas por la Organización Mundial de la Salud (OMS), el Centro para el Control y Prevención de Enfermedades (CDC), la Administración para la Seguridad y Salud Ocupacional (OSHA), la Asociación Dental Americana (ADA) y el Ministerio de la Protección Social en Colombia. Con el objeto de disminuir o eliminar el riesgo de contaminación con infecciones como el VIH, entre otras, se ha estipulado que las fuentes de contaminación en la consulta odontológica pueden ser de tres vías: de paciente a odontólogo, de odontólogo a paciente y de paciente a paciente.

La contaminación disminuye de manera importante con la utilización de barreras, tales como:

- Desinfectar escupideras y superficies con bactericidas.

- Cubrir las superficies con plástico o aluminio (pre y postlimpieza).

- Desinfectar batas, mandiles o desechables.

- Usar tapaboca, anteojos o máscara.

- Usar guantes, teniendo en cuenta lavar las manos con agua y jabón antes y después de la atención.

- Esterilizar o desinfectar el instrumental crítico (esterilizar), semicrítico (esterilizar o desinfectar) o no crítico (desinfectar). 
- Todo el instrumental debe ser neutralizado en una solución de hipoclorito de sodio al $5,25 \%$ ( $1 / 4$ de taza de hipoclorito de sodio/ galón de agua), previo al lavado.

El protocolo de riesgo biológico incluye, igualmente, el esquema de vacunación previo a la atención de cualquier paciente contra VHB, influenza, sarampión, rubéola, tétano y tuberculosis (TBC).

La implementación de las precauciones universales también protege al personal de salud de infecciones de las vías respiratorias, como el resfriado común, la sinusitis aguda, la faringitis aguda, la neumonía y la TBC, entre otras; de enfermedades de la niñez, como la varicela, fiebre aftosa, sarampión, rubéola, parotiditis y citomegalovirus, y de enfermedades que se consideran de transmisión sexual pero que pueden ser trasmitidas por vía oral, tales como infecciones herpéticas, gonorrea, clamidia, tricomonas, condiloma acuminado, sífilis, mononucleosis, hepatitis y VIH/SIDA. Por todo lo anterior, las precauciones universales deben ser utilizadas rutinaria y consistentemente $(13,14,15)$.

El manejo de la herida secundaria a un accidente de trabajo, incluye la limpieza con agua y jabón (no se debe utilizar cepillo ni hipoclorito de sodio por el riesgo de excoriación), la utilización de un antiséptico local y el tratamiento antirretroviral.

Aunque no es específico para los pacientes VIH positivos, se debe tener en cuenta que la boca está colonizada por numerosos microorganismos y que cualquier procedimiento, rutinario o no, abre una puerta de entrada al sistema vascular y a las áreas normalmente estériles (hueso y tejido celular subcutáneo, por ejemplo). La evidencia científica no ha demostrado prevención de infecciones al utilizar enjuagues bucales o realizar cepillado antes de un procedimiento odontológico con productos antimicrobianos como la clorexidina o la yodopovidona, pero sí se sabe que puede reducir el nivel de microorganismos presentes en los aerosoles o salpicaduras durante el tratamiento, al igual que protege al paciente, porque disminuye el número que puede pasar al torrente circulatorio, controlando el riesgo de sobreinfección, especialmente en los pacientes inmunocomprometidos(16).

Establecer la rutina de evaluar, controlar y prevenir accidentes de trabajo, y de infecciones asociadas a la práctica odontológica, al igual que el manejo integral del paciente, dentro de un esquema que incorpora al equipo de salud, garantiza mejor atención y calidad de vida, no solamente para las personas portadoras del VIH/ SIDA, sino para los pacientes en general.

\section{Referencias}

1. Organización Mundial de la Salud. Informe sobre salud en el mundo. Ginebra: OMS: 2004.

2. Instituto Nacional de Salud de Colombia. Informe evento VIH/SIDA. Semanas epidemiológicas 1 a 12. Primer trimestre. 2005.

3. Beltrán M, Acosta J, Rojas MC, Velandia MP. V Estudio Centinela Nacional de Vigilancia de Infección por VIH-1, Colombia: Ministerio de Salud, Dirección General de Promoción y Prevención, Oficina de Epidemiología. Instituto Nacional de Salud, subdirección de Epidemiología y Laboratorio Nacional de Referencia; 1999.

4. Secretaría de Salud Pública Municipal de Cali. Cali Saludable, Salud Sexual y reproductiva. 2005 [Sitio en Internet] Disponible en: http://www.calisaludable.gov.co/saludPublica/salud_sexual.php 
Atención al paciente VIH/SIDA: Legislación y bioseguridad odontológica en Colombia - B. Acosta de Velásquez

5. Cardona E, y col. Morbilidad atendida en la clínicas del Colegio Odontológico Colombiano Extensión Santiago de Cali 200-2004. Tesis de grado.

6. World Medical Association. Declaration of Helsinki. Ethical Principles for Medical Research Involving Human Subjects. 1964 [Sitio en Internet] Disponible en http://www.wma.net/e/policy/b3.htm

7. República de Colombia. Ministerio de la Protección Social. Decreto 1.543 de 1997.

8. República de Colombia. Ministerio de la Protección Social. Resolución 412 de 2000.

9. República de Colombia. Código de Ética del Odontólogo Colombiano. Ley 35 de 1989.

10. República de Colombia. Código de Ética Médica. Ley 23 de 1981.

11. República de Colombia. Ministerio de Salud. Ley 100 de 1990.

12. Harrison's. Principles of Internal Medicine. 16th Edition. London: McGraw-Hill; 2005: 1081-1087.

13. Organización Mundial de la Salud. La salud bucodental: repercusión del VIH/SIDA en la práctica odontológica. Washington, DC: OMS; 1995.

14. Seguro Social. Vigilancia epidemiológica para factores de riesgo biológico en personal de salud. Bogotá: Administradora de riesgos profesionales; 2002.

15. Seguro Social. Administradora de riesgos profesionales. Protocolo de vigilancia epidemiológica en riesgo biológico de origen ocupacional. Bogotá. 2002.

16. Centers for Disease Control and Prevention. Guidelines for Infection Control in Dental Health-Care Settings - 2003. MMWR 2003; 52.

Recibido: 01 de marzo de 2006

Aceptado: 31 de marzo de 2006 